\title{
A Phase II/III, randomized, double-masked, vehicle-controlled, dose-ranging study of the safety and efficacy of OTX-IOI in the treatment of dry eye disease [Corrigendum]
}

Tauber J, Schechter BA, Bacharach J, et al. Clin Ophthalmol. 2018;12:1921-1929.

On page 1924, Efficacy end points, Conjunctival staining section, the sentence "Statistically significant reductions in the mean change from baseline in the study eye at Day 84 relative to vehicle were observed for both OTX-101 concentrations $(P<0.01)$. The results by study visit are depicted in
Figure 3." should read "Statistically significant reductions in the least squares mean change from baseline in the study eye at Day 84 relative to vehicle were observed for both OTX-101 concentrations $(P<0.01)$. The results by study visit are depicted in Figure 3."

On page 1926, Figure 3 and captions should be replaced as follows:

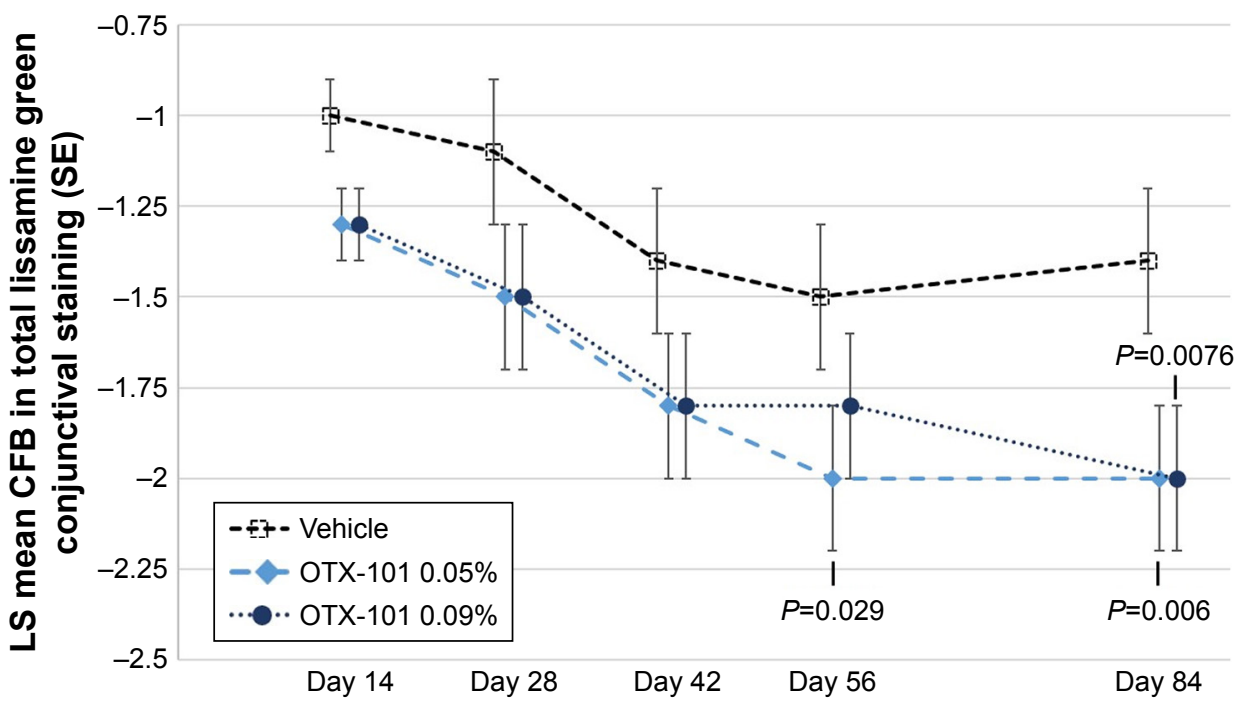

Figure 3 The LS mean CFB in total conjunctival lissamine green staining scores by study visit is presented for the vehicle group (open squares), OTX-I0I $0.05 \%$ group (light blue diamonds) and OTX-10I $0.09 \%$ group (dark blue circles).

Notes: Statistically significant reductions in the LS mean CFB relative to vehicle were observed for OTX-10I $0.09 \%$ at Day 84 ( $P=0.0076$ ), and for the OTX-10I $0.05 \%$ group at Day $56(P=0.029)$ and Day $84(P=0.006)$.

Abbreviations: CFB, change from baseline; LS, least squares; SE, standard error.

Clinical Ophthalmology

\section{Publish your work in this journal}

Clinical Ophthalmology is an international, peer-reviewed journal covering all subspecialties within ophthalmology. Key topics include: Optometry; Visual science; Pharmacology and drug therapy in eye diseases; Basic Sciences; Primary and Secondary eye care; Patient Safety and Quality of Care Improvements. This journal is indexed on

PubMed Central and CAS, and is the official journal of The Society of Clinical Ophthalmology (SCO). The manuscript management system is completely online and includes a very quick and fair peer-review system, which is all easy to use. Visit http://www.dovepress.com/ testimonials.php to read real quotes from published authors. 